\title{
What pricing and reimbursement policies to use for off-patent biologicals? - Results from the EBE 2014 biological medicines policy survey
}

\author{
European Biopharmaceutical Enterprises
}

Objective: One of the questions that the advent of biosimilars raises is whether the different nature of biological medicines would also imply the need for a different policy approach by Member States in the European Union (EU). To assess the policy environment the European Biopharmaceutical Enterprises (EBE) conducted a brief descriptive policy survey of pricing and reimbursement policies for off-patent biologicals.

Methods: EBE conducted a survey in 31 countries, the 28 EU Member States plus Norway, Serbia and Switzerland. The questionnaire was developed by the EBE Biosimilars Working Group and contained 24 questions about five policy areas: Tendering, Health Technology Assessment, International Nonproprietary Name (INN) prescribing, Internal Reference Pricing, and Substitution. The focus was on the most relevant policies which: a) were applied to the off-patent market; and b) were of specific relevance for biological medicines.

Results: No country required substitution of patients on treatment at the time of the survey. Nearly two thirds of the countries have either laws or guidelines in place that prohibit substitution of biological medicines. In 12 countries it is possible for patients on a given treatment to be changed to a different product due to tender outcomes. While prescribing by INN is mandatory or recommended in 13 of 31 countries the majority of countries have introduced mechanisms to exempt biological medicines from INN prescribing.

Conclusion: This initial high-level survey of EBE indicates that nearly all jurisdictions have policies in place that reflect the different nature of biological medicines. However, policies and their implementation vary among different jurisdictions.

\section{Keywords: Biological medicines, biosimilars, off-patent market, pricing and reimbursement policy}

\section{Introduction}

Pharmaceutical pricing and reimbursement policies aim to improve the rational use of medicines and keep pharmaceutical spending under control [1]. In the European Union (EU), the design and implementation of pharmaceutical policies are in the competence of Member States as laid down in the Treaty [2]. Decisions about price and reimbursement of prescription medicines are usually made by governments but also by social funds or private payers. One particular area of interest for pharmaceutical policy is the off-patent market since, with patent expiration, many follow-on medicines both small-molecule generics and biosimilars can enter the market and compete with the originator products. Approximately, Euros 35 billion are saved yearly by the use of small-molecule generics alone, according to the European Generic medicines Association [3].

As an increasing number of biosimilars will soon be available due to patent expiration, the expectations of Member States to generate savings are high. The market for biological products accounted for Euros 36 billion in 2011 [4]. Biological medicines today account for $27 \%$ of all pharmaceutical sales in Europe; eight of the top 10 selling medicines are biologicals [5]. Although this is still much less than the market for non-biological products (Euros 107 billion), growth has been at a rate of $7 \%$ while the non-biological products market grew at 1\%. Between 2006 and 2014, 21 biosimilars were approved by the European Medicines Agency (EMA); two biosimilars have been withdrawn (2008 and 2012) for commercial reasons. The remaining 19 biosimilars on the market represent 12 authorized biosimilar molecules; by commercial agreement, several of these products are registered under two or more trade names [6, 7]. Today, the majority of biological products are still patent protected and thus not yet exposed to biosimilar competition [8]. However, this will change in the next few years when many top-selling products will lose their patent protection [5].

Pharmaceutical policies for the off-patent market for smallmolecule generics traditionally included a variety of measures related to pricing, reimbursement, market entry and expenditure controls but also measures targeting distributors, physicians and patients [1]. Some of the most common policies involve generics substitution, Internal Reference Pricing (including Generic Reference Pricing and Therapeutic Reference Pricing), prescribing by International Nonproprietary Name (INN), often linked with the obligation for pharmacists to dispense the cheapest medicine available with the same INN, and finally also procurement practices, such as tendering, see Table 1.

Biosimilars are not the same as generics, which have simpler chemical structures and are considered to be identical to their reference medicines [9, 10]. One of the questions raised by the advent of biosimilars was therefore whether the different nature of biological medicines was also reflected in a different policy approach in terms of pricing and reimbursement by EU Member States. This question prompted the European Biopharmaceutical Enterprises (EBE) to conduct a biologicals policy survey across EU Member States, including Norway, Serbia and Switzerland

Author for correspondence: Alexander Roediger, MSD Europe Inc, 5 Clos du Lynx, BE-1200 Brussels, Belgium

Submitted: 14 December 2014; Revised: 11 February 2015; Accepted: 12 February 2015; Published online first: 25 February 2015 
Table 1: Definitions

The Consensus Information Document 'What you need to know about biosimilars' provides definitions that can be considered standard as they are supported by most of the stakeholders. However, these definitions were not available when the survey was conducted so that the definitions used for the survey were based on the EBE position on Substitution, published in 2011. For obvious reasons, they may differ in some cases. We do not believe that this impacts the results; but for transparency we add both definitions where available.

Generics substitution: Pharmacists may be induced or mandated to dispense the cheapest bioequivalent medicine, which is often called 'generics substitution' [1].

Internal Reference Pricing: Internal Reference Pricing typically means determining the maximum price for medicinal products and the maximum reimbursement rate for each medicine by grouping them and calculating the price, e.g. average, lowest [1], see also 'Reference Group'.

Reference Group: A group of medicines of the same active ingredient (ATC 5), in a given therapeutic class (ATC 4) or clustered based on a broader definition but still considered interchangeable. These clusters of medicines form the basis for establishing a reference price system [35]. Depending on the ATC level the pricing mechanism is called Generic Reference Pricing (ATC 5, active substance level) or Therapeutic Reference Pricing (ATC 4 and above) [23].

Substitution: The practice by which a product other than the one specified on the prescription is dispensed to the patient, without the prior informed consent of the treating physician. A variation of substitution is practiced in some countries, where, if the physician prescribes by International Nonproprietary Name, the pharmacist may decide to dispense any product with the same active ingredient [36]. Practice of dispensing one medicine instead of another equivalent and interchangeable medicine at the pharmacy level without consulting the prescriber.

Switching: The decision of a physician to change the patient from one medicine to another medicine with the same therapeutic intent, in order to optimize therapy and reduce adverse effects [36]. Decision by the treating physician to exchange one medicine for another medicine with the same therapeutic intent in patients who are undergoing treatment.

Tender: The procurement means by which products or services (in the present case pharmaceuticals) are acquired based on a competitive bidding process, where the contract is granted to the supplier who offered the best bid following strict criteria specified in advance [30].

ATC: Anatomical Therapeutic Chemical.

According to EMA, approved biosimilars and their respective reference medicinal products are expected to have the same safety and efficacy profile and are generally used to treat the same conditions. Nevertheless, due to the specific nature of biological medicines, questions have arisen about their suitability for substitution, see Table 1. These questions have been subsequently mentioned or discussed in various documents. The Questions and Answers of EMA and the Guideline on Similar Biological Medicinal Products state that the agency's evaluations do not include recommendations on whether a biosimilar should be used interchangeably with its reference medicine [11]. The document further states that for questions related to switching from one biological medicine to another, patients should speak to their doctor and pharmacist. The EMA Procedural Advice specifies that the decisions on interchangeability and/or substitution rely on national competent authorities and are outside the remit of EMA's Committee for Medicinal Products for Human Use (CHMP). [12]. EU Member States have access to the scientific evaluation performed by the CHMP and all submitted data in order to substantiate their decisions. Whether biosimilars can or should be used interchangeably is therefore left to the responsibility of each Member State. This approach is echoed by the Biosimilars Working Group of the Platform on Access to Medicines in Europe which excluded a discussion on the substitution of biosimilars from their terms of reference [13].

As a consequence from the medical implications of biological medicines, literature suggested that biosimilar competition would most probably differ from small-molecule generics competition [14]. But various reasons for this include also development and production costs for biological medicines, more complex regulatory and scientific reviews in the marketing authorization process, additional pharmacovigilance requirements, and increased efforts in education of prescribers. The latter, education and understanding by stakeholders, was also one of the key elements mentioned in a recent GfK report about the factors needed to create a sustainable European biosimilar medicines market [15].

\section{Methods}

EBE conducted a survey in 31 countries, the 28 EU Member States plus Norway, Serbia and Switzerland. The questionnaire contained 24 questions about the following five policy areas: Tendering, Health Technology Assessment (HTA), INN prescribing, Internal Reference Pricing, and Substitution, see Table 2. The policy areas were selected based on a list of 23 different policies discussed in the Economic Paper 461 'Cost-containment policies in public pharmaceutical spending in the EU' of the Directorate-General for Economic and Financial Affairs (DG ECFIN) [1]. For some of the policies, specific definitions were provided, see Table 1 .

The survey questionnaire was developed by the EBE Biosimilars Working Group and focuses on the most relevant policies which: a) applied to the off-patent market; and b) were of specific relevance for biological medicines. As a consequence, policies establishing or allowing substitution were of main interest, e.g. Internal Reference Pricing, INN prescribing or tendering. In addition, as the intention was to gain a brief descriptive overview of a range of different policies as well as a complete and comparable coverage for Europe, the questionnaire focused on a limited number of questions, 24 in total.

Information for specific countries was based on individual comments or available literature and was used to supplement the findings. Finally, the survey included only questions about biological medicines and did not collect information about generics policies. The questionnaire was available in English only. 


\section{Table 2: Questions}

\section{Tendering}

Are biological medicines part of tenders?

If not, is it likely that they are included in tenders in the future?

If biological medicines are part of tenders, are the tenders covering:

a) a whole therapeutic area (therapeutic tenders)

b) only ATC 5 level; or

c) both?

If biological medicines are part of tenders, is the tender: a) outpatient; b) hospital; c) both?

If biological medicines are part of tenders, are these tenders: a) 'single win'; or b) 'multiple win'?

If biological medicines are part of tenders, does this lead to switches of: a) new patients; b) new patients and patients on treatment?

\section{Health Technology Assessment (HTA)}

Are biosimilars undergoing HTA?

If not, is it likely that they will undergo HTA in the near future?

If biosimilars undergo HTA, is this mandatory?

Is HTA done by indication?

\section{INN prescribing}

Is INN prescribing: a) mandatory; b) recommended; c) not in place;

d) brand or INN prescribing is at the discretion of the prescribing physician?

If INN prescribing is: a) mandatory; or b) recommended, are biologicals included?

Does this lead to switches, i.e. substitution, of patients already on treatment in the outpatient care?

Does this lead to switches, i.e. substitution, of patients already on treatment in the inpatient care?

If INN prescribing is not in place, what is the likelihood that INN prescribing is introduced? a) high; b) medium; c) low

\section{Internal Reference Pricing (IRP)}

Are biological medicines part of IRP mechanisms?

If yes, what type? (Therapeutic or Generic Reference Pricing?)

If yes, does this lead to switches, i.e. substitution, of patients on

treatment in the outpatient care?

If yes, does this lead to switches, i.e. substitution, of patients on treatment in the inpatient care?

\section{Substitution}

Are biologicals undergoing substitution? (pharmacy-level substitution)

If yes, is the prescriber informed?

If no, at what level is substitution prohibited? a) guideline; b) law; c) not regulated

How likely is it that substitution is introduced? a) high; b) medium; c) low

To pilot the survey instrument, EBE members shared the questionnaire with their respective company affiliates. Following their initial feedback the questions were adapted where necessary. The questionnaire was then sent to national pharmaceutical associations (two mailings with a third mailing to associations which had not yet responded). For five associations, individual phone calls were held to ensure clearer understanding of the responses. The survey did not include any reimbursement or payments for participation.

EBE received responses from 29 national pharmaceutical associations (a 94\% response rate) and from two member companies (6\%); the latter submitted data from Malta and Romania. Data was collected between September 2013 and March 2014.

\section{Results}

\section{Substitution}

Nearly two thirds, i.e. 20 out of 31 countries have either laws or guidelines in place that prohibit substitution of biological medicines, see Figure 1. However, substitution of biological medicines at the pharmacy-level can happen in two out of 31 countries (Estonia, Poland). No change of the current policies is expected in the near future and more than half of the respondents ( 16 out of 28 responses received) considered the possibility of introduction of substitution as unlikely.

It has to be noted that the French Parliament passed into law the 2014 Social Security Bill (PFSS) in December 2013 that contains provisions to permit a restricted form of pharmacylevel substitution for 'naïve patients', i.e. limiting any substitution of any similar biologicals medicines to those patients who are being started on a new treatment course [16]. The law makes clear that patients who have already commenced treatment must not have their medicine substituted by a pharmacist [17]. Currently, the implementation of this measure is still being developed.

A different situation exists in Poland: the Polish reimbursement law does not distinguish between small-molecule generics and biosimilars, including for the purposes of applying its pharmacy-level substitution policy. Under current arrangements, a medicine can be substituted with another when it satisfies specific criteria, including that the products contain the same active substance (defined as same INN), are reimbursed for the same indication and are considered therapeutically equivalent (defined as non-inferior safety and efficacy) [18]. On this basis, the Polish authorities authorize a change in the treatment for patients to infliximab biosimilar from the infliximab originator, and shifting patients from one to another infliximab product does not require the direct supervision of the physician [19].

While only clarified in a letter, in applying its substitution policies to biological medicines, Poland is out of step with nearly all

\section{Figure 1: Legal status of substitution}

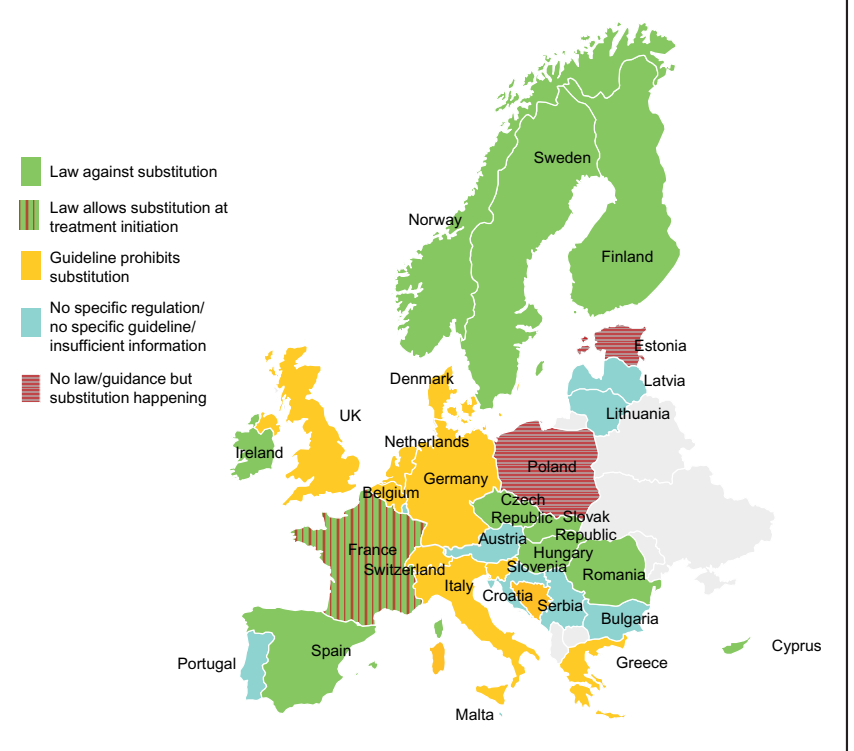


EU countries. France, Germany, Italy and Spain have all declared that similar biological medicines cannot be substituted at the pharmacy level [16, 20-22]. France and Italy have explicitly identified initiating or 'naïve' patients as the appropriate population for substitution, stressing the principle of continuation of therapy.

\section{Tendering}

In the majority of countries, biological medicines are subject to tenders (24), see Figure 2. In 13 of them the scope is ATC 5, i.e. substance-level only. The majority of tenders with biologicals are hospital tenders only (18). In 12 (23 responses received) countries it is possible that patients on a given treatment are changed to a different product due to tender outcomes. Many respondents reported that 'usually' physicians are involved in the decisionmaking. Respondents from Germany, for example, noted that the tendering may lead to switches but this was not systematic and would rather depend on the decision of the treating physician.

\section{Health Technology Assessment (HTA)}

In 12 out of 29 countries biosimilar medicines undergo HTA. In Finland, biosimilars do not undergo HTA in hospitals but do in the outpatient care setting where a simple price-cost comparison with all other medicinal products used for treating the same disease, including the reference medicine, is undertaken. Slovakia has no requirement for HTA for biosimilars. However, if a biosimilar applies for pricing and reimbursement in an indication for which the reference product is not reimbursed then HTA is required.

\section{INN prescribing}

Prescribing biological medicines by INN can lead to substitution of patients on treatment since the INN used by the biosimilar is in most cases the same as the one designated by World Health Organization (WHO) for the reference product. While INN prescribing is mandatory or recommended in 13 out of 31 countries, the large majority of countries have introduced mechanisms to exempt biological medicines from prescribing by INN.

Figure 2: Tenders which contain biological medicines

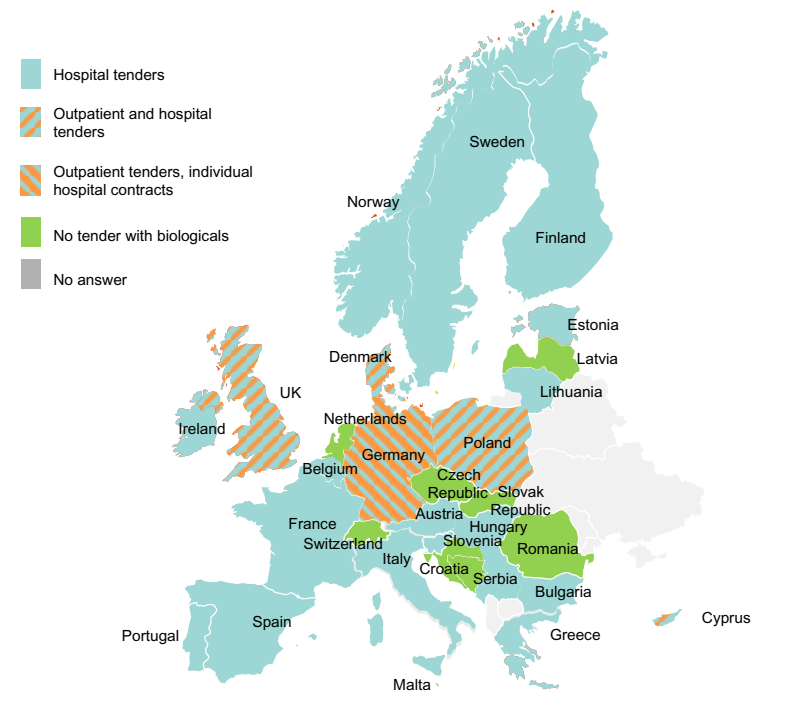

In practice, the distinction between small-molecule generics and biologicals - off-patent originators and biosimilars - is often blurred. UK has a strong tradition of INN prescribing and physicians also apply this to biologicals so that this common practice may result in unintentional substitution of biological medicines. In Lithuania, the INN should be used for all new medications included in the 'List A' (interchangeable) with the brand name in brackets. The biosimilar infliximab and the reference product have been part of that list since January 2014. Other biologicals; however, are not on that list and in those cases the brand name can be used. Finally, in Portugal, biologicals are not exempted from mandatory INN prescribing; this means that the physician has to indicate, always by his/her own initiative, that the patient's medication should not be substituted.

\section{Internal Reference Pricing (IRP)}

In almost half of the countries (15) biologicals are included in IRP. Eight of these countries apply Therapeutic Reference Pricing, creating reference groups at the level of the therapeutic class or higher (ATC 4 or higher). Six countries have reference pricing at active substance level (ATC 5; Generic Reference Pricing) in place, see Figure 3. Other countries may have excluded biologicals explicitly from IRP or do not have this policy at all [23].

IRP typically means determining the maximum price for medicinal products and the maximum reimbursement rate for each medicine by grouping them and calculating the price (average, lowest, etc., see Table 1). In six of 15 countries switches can happen due to IRP.

\section{Limitations}

The survey has several limitations. As the intention was to get a brief descriptive overview of a range of different pricing and reimbursement policies for biological medicines across Europe, the questionnaire was kept brief and limited to 24 questions. The survey included only questions about biological medicines and did not poll generics policies in the respective countries. Although such 
a comparison would have been interesting in light of the different uptake patterns, it would have made the survey unwieldy and likely would have made it very difficult to get a timely and complete response rate. However, this is clearly an area for further research and we hope that this initial review contributes to that pursuit.

We also acknowledge that the questions, see Table 2, were general by nature and were not able to probe the details and interdependencies around those policies. However, many respondents added country-specific comments.

Another limitation is that we did not differentiate between substitution of new patients and patients on treatment as this was less relevant when the survey started. However, to ensure that the main results are meaningful we have presented the responses to the questions, which could be clearly interpreted. For substitution, the results presented are for the question of what kind of regulatory measures in terms of prohibiting substitution were in place, i.e. laws, guidelines or no regulation at all.

\section{Discussion}

The results of this initial EBE policy survey show that countries differ in terms of pharmaceutical policies for biological medicines. A majority of the countries have specific policies in place acknowledging the different nature of biological medicines compared with small-molecule medicines.

At the same time, there is also a great variation between countries and the level of detail in their respective policy frameworks. Ten countries have no explicit regulation concerning substitution of biological medicines so there is a risk that other policies or recommendations could lead to unintended patient treatment changes. However, this does not necessarily mean that biosimilar substitution would not be regulated in these countries. Sometimes it is regulated at a higher level as for example in Austria where doctors must prescribe all medicinal products by brand name and pharmacists must dispense the prescribed medicinal product in a valid prescription. Therefore, pharmacists cannot legally substitute prescribed medicinal products at their own discretion [24, 25]. Noteworthy also is the fact that even some of the most recent literature discussing pharmaceutical policies and cost containment do not mention biosimilars at all or if so only very briefly [1, 26-28].

Traditionally, substitution has played an important role in the offpatent market for small-molecule generics. Generics substitution is used in many countries to increase market efficiency: in 2012 it was mandatory in eight, indicative, i.e. not required but encouraged, in 14 and disallowed in seven EU Member States [1]. For biosimilars, the situation looks different as explained above: biosimilars are not the same as generics, and EMA's evaluations do not include recommendations as to whether a biosimilar should be used interchangeably with its reference medicine but rather leave the decision to Member States. Aside from the specific situations in France and Poland discussed above, according to the EBE survey no Member State requires substitution.

Whether this will change remains to be seen. The recently launched study that is supported by the Norwegian Government to assess a one-time switch from the originator biological to its biosimilar product will not assess interchangeability [29]. However, the conduct of such a study suggests, the authors believe, that scientific evidence should be a requirement for allowing a change in a treatment with a biological medicine. The fact that interchangeability is mentioned in the EMA documents but not part of the biosimilar regulatory assessment by EMA, coupled with the different regulations in Member States, indicates that the decision about the advisability of substitution is not straightforward.

Questions concerning substitution have implications for many other pharmaceutical policies including tenders, INN prescribing and IRP. In the small-molecule generics market such policies aim at substituting patients using the sole criterion of price to ensure that the cheapest available medicine with the same INN is used, e.g. Poland. To prevent substitution of biological medicines for non-medical reasons several organizations have taken positions on tendering of biological medicines where they suggest that tenders have to be carefully designed to ensure that patients on biological treatments are not automatically substituted [30, 31].

To create savings and ensure an efficient off-patent market for biological medicines competition is a critical factor. The Consensus Information Document [13] which was developed by a multi-stakeholder project group, in close cooperation with the Commission services, states in this regard that: 'It is important to note that biosimilar market uptake has been possible despite the fact that substitution between the biosimilar and its reference medicinal product is not practiced at the pharmacy level' [13].

The same publication mentions potential factors involved in uptake, such as physician perception of biosimilar medicines, patient acceptance of biosimilar medicines, local pricing and reimbursement regulation, procurement policies and terms, and concludes: 'It is thus essential that physicians and patients share a thorough understanding of biological medicines, including biosimilar medicines, and express confidence in using either type of therapy. This can be achieved by maintaining a robust regulatory framework and effective risk management, transparency with regard to biological medicinal products, and continued education on biological medicines, including biosimilar medicines' [13]. The fact that multiple factors play a role in competition in the off-patent market for biologicals has been confirmed by a recent report from IMS Health [5].

That uptake is also correlated with culture was reported by Grabowski et al. when comparing different markets with regard to biosimilars: uptake in countries with low rates of generics competition like France and Italy seem also to have a lower uptake of biosimilars - in contrast to countries like Germany or the UK [32]. The only exemption was in the G-CSF market, and there have been some hypotheses put forth about the reasons for this difference, which focus on its short-term therapeutic use as supportive care. In changing behaviour trust plays an important role; good information is one element needed to create trust [13]. A recently published survey among European physicians confirmed the need for more and better education [33].

Off-patent market policies for pricing and reimbursement of biological medicines should be formulated in a holistic manner, i.e. reflect the full ecosystem of pharmaceutical innovation. Instead of pure uptake measures they should promote competition, which means they should ensure proper exclusivity rights but also swift market entry of competitors after Marketing Authorization. Such competition has to be sustainable and should generate savings for healthcare 


\section{Table 3: Data}

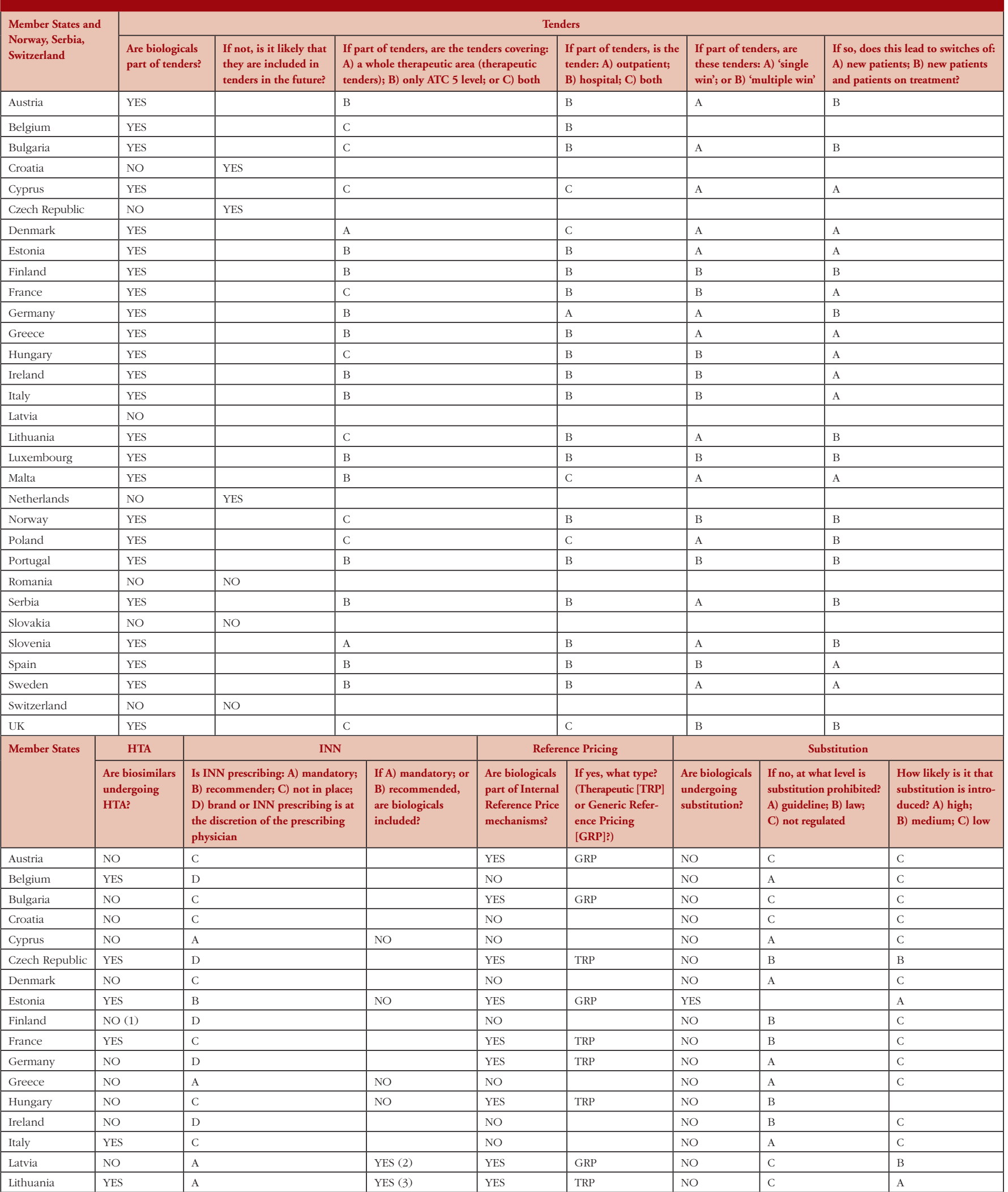




\section{Table 3: Data (Continued)}

\begin{tabular}{|c|c|c|c|c|c|c|c|c|}
\hline Luxembourg & NO & C & & NO & & NO & C & C \\
\hline Malta & NO & A & NO & NO & & NO & C & B \\
\hline Netherlands & NO & B & NO & YES & TRP & NO & A & B \\
\hline Norway & YES & B & NO & NO & & NO & B & B \\
\hline Portugal & YES & A & YES (4) & NO & & NO & C & B \\
\hline Romania & YES & A & NO & YES & TRP & NO & B & \\
\hline Serbia & $\mathrm{Na}$ & $\mathrm{C}$ & & YES & GRP & NO & $\mathrm{C}$ & C \\
\hline Spain & NO & B & NO & YES & GRP & NO & B & B \\
\hline Sweden & YES & C & & NO & & NO & B & C \\
\hline Switzerland & NO & $\mathrm{D}$ & & NO & & NO & A & C \\
\hline UK & YES & B & NO & NO & & NO & A & C \\
\hline
\end{tabular}

(1) Comment from Finland: For hospitals, no HTA needed. For new biosimilars in the outpatient care, simple price/cost comparison with a reference medicine, etc.; is provided in the reimbursement dossier. (2) Comment provided by Latvia: Only for new patients if they are in the list A. (3) Comment from Lithuania: The physician has a right to write a brand name in brackets and this is only allowed for biologicals. (4) Comment from Portugal: Biologicals are not exempted from mandatory INN prescribing; this means that the physician has to indicate always by his own initiative that the patient should not be substituted.

HTA: Health Technology Assessment; INN: International Nonproprietary Name.

systems without compromising medical standards. The sustainability of biologicals policies becomes particularly relevant as recent research of Leopold et al., for example, suggests that in the field of small-molecule generics policy changes happened very frequently due to the economic recession: between 2008 and 2011 economically stable countries implemented two to seven policy changes each, whereas less stable countries implemented 10 to 22 each [34].

From a broader perspective, early access to innovative medicines and incentives for sustainable medical innovation, e.g. data exclusivity, sound demand-side policies, also need to be ensured. The differences between biosimilars and small-molecule generics should also be reflected in the policy approach. Efficient and sustainable markets for biologicals after patent expiry require a balance between payers' policies, the attitudes of healthcare providers and patients, and sound competition. Policies need to be sustainable, i.e. create trust among healthcare providers and patients through information and a strong regulatory framework, e.g. EMA, and reflect the 'Cost of Development', regulatory requirements (including post marketing) and facilitate long-term competition.

\section{Conclusion}

This first descriptive EBE survey of pricing and reimbursement policies for biological medicines indicates that nearly all jurisdictions have policies in place that reflect the different nature of biological medicines. However, policies and their implementation vary among different jurisdictions.

Competing interests: This paper is authored and funded by European Biopharmaceutical Enterprises (EBE) and represents the policies of the organization.

EBE is the European trade association that represents biopharmaceutical companies of all sizes operating in Europe. Membership is open to all companies using biotechnology to discover, develop and bring new medicinal products to market. For more information: www.ebe-biopharma.eu/

Provenance and peer review: Not commissioned; externally peer reviewed.

\section{Contributing authors from EBE}

Virginia Acha, DPhil, Director Global Regulatory and R \& D Policy Europe, Middle East and Africa, Amgen

Piers Allin, Director Regulatory Affairs, European Biopharmaceutical Enterprises

Stefan Bergunde, Diplom-Kaufmann (MBA), Strategic Initiatives Europe, AbbVie

Fabio Bisordi, MSc, Regulatory Franchise Head, F. Hoffmann-La Roche Ltd

Alexander Roediger, MA USZ, Executive MBA HSG, Director European Union Affairs, MSD Europe Inc

\section{References}

1. European Commission. Carone G, Schwierz C, Xavier A. Cost-containment policies in public pharmaceutical spending in the EU. Economic Papers 461. 2012 [homepage on the Internet]. 2012 Sep 27 [cited 2015 Feb 11]. Available from: http://ec.europa.eu/economy_finance/publications/economic_paper/ 2012/pdf/ecp_461_en.pdf

2. European Union. Eur-Lex. Treaty of the Functioning of the European Union, Art. 168(7); Official Journal (9.5.2008) C 115/47-199 [homepage on the Internet]. [cited 2015 Feb 11]. Available from:http://eur-lex.europa.eu/ legal-content/EN/TXT/?uri=CELEX:12012E/TXT

3. European Generics medicines Association. Napolitano S. EGA Fact Sheet on generic medicines. Every year Generic medicines bring savings of $€ 35 \mathrm{BN}$ to the EU 27 [homepage on the Internet]. 2013 Nov 13 [cited 2015 Feb 11]. Available from: http://www.egagenerics.com/images/EGA_factsheet_09.pdf

4. European Commission. IMS. Dunn C. Biosimilar accessible market: size and biosimilar penetration. Prepared for EFPIA-EGA-EuropaBio, April 2012 [homepage on the Internet]. [cited 2015 Feb 11]. Available from: http://ec.europa. eu/enterprise/sectors/healthcare/files/docs/biosimilars_imsstudy_en.pdf

5. IMS Health. Assessing biosimilar uptake and competition in European markets. October 2014 [homepage on the Internet]. 2014 Oct 8 [cited 2015 Feb 11]. Available from: http://www.imshealth.com/imshealth/Global/Content/Corporate/IMS\%20Health\%20Institute/Insights/Assessing_biosimilar_ uptake_and_competition_in_European_markets.pdf

6. European Medicines Agency. European public assessment reports [homepage on the Internet]. [cited 2015 Feb 11]. Available from: http://www.ema.europa. eu/ema/index.jsp?curl=pages $\% 2$ Fmedicines $\% 2$ Flanding $\% 2$ Fepar_search.jsp\& 
mid=WC0b01ac058001d124\&searchTab=searchByAuthType $\&$ alreadyLoaded= true\&isNewQuery=true\&status=Authorised\&keyword=Enter+keywords\& searchType=name\&taxonomyPath $=\&$ treeNumber $=\&$ searchGenericType $=$ biosimilars\&genericsKeywordSearch=Submit

7. Walsh G. Biopharmaceutical benchmarks 2014. Nat Biotechnol. 2014;32(10): 992-1000

8. GaBI Online - Generics and Biosimilars Initiative. Biosimilars approved in Europe [www.gabionline.net]. Mol, Belgium: Pro Pharma Communications International; [cited 2015 Feb 11]. Available from: www.gabionline.net/ Biosimilars/General/Biosimilars-approved-in-Europe

9. European Medicines Agency. Questions and answers on biosimilar medicines (similar biological medicinal products). EMA/837805/2011. 27 September 2012 [homepage on the Internet]. 2012 Sep 27 [cited 2015 Feb 11]. Available from: http://www.ema.europa.eu/docs/en_GB/document_library/Medicine_ QA/2009/12/WC500020062.pdf

10. Weise M, et al. Biosimilars: the science of extrapolation. Blood. 2014;124(22) 3191-6.

11. European Medicines Agency. Guideline on similar biological medicinal products. CHMP/437/04 Rev 1. 23 October 2014 [homepage on the Internet]. 2014 Oct 30 [cited 2015 Feb 11]. Available from: http://www.ema.europa.eu/docs/ en_GB/document_library/Scientific_guideline/2014/10/WC500176768.pdf

12. European Medicines Agency. EMA Procedural advice for users of the Centralised Procedure for Similar Biological Medicinal Products applications. EMA/940451/2011. October 2014 [homepage on the Internet]. 2014 Oct 29 [cited 2015 Feb 11]. Available from: http://www.ema.europa.eu/docs/ en_GB/document_library/Regulatory_and_procedural_guideline/2012/04/ WC500125166.pdf

13. European Commission. What you need to know about biosimilar medicinal products. A consensus information document [homepage on the Internet]. 2013 Apr 24 [cited 2015 Feb 11]. Available from: http://ec.europa.eu/ enterprise/sectors/healthcare/files/docs/biosimilars_report_en.pdf

14. Farfan-Portet MI, Gerkens S, Lepage-Nefkens I, Vinck I, Hulstaert F. Are biosimilars the next tool to guarantee cost-containment for pharmaceutical expenditures? Eur J Health Econ. 2014;15(3):223-8.

15. European Generic medicines Association. GfK Market Access. Factors supporting a sustainable european biosimilar medicines market [homepage on the Internet]. 2014 Sep 9 [cited 2015 Feb 11]. Available from: http://www.egagenerics.com/index.php/publications/342-gfk-final-report-factors-supportinga-sustainable-european-biosimilar-medicines-market

16. Conseil Consitutionnel. Décision n 2013-682 DC du 19 décembre 2013 [homepage on the Internet]. [cited 2015 Feb 11]. Available from: http:// www.conseil-constitutionnel.fr/decision/2013/2013-682-dc/decision-n2013-682-dc-du-19-december-2013.138972.html

17. European Biopharmaceutical Enterprises. EBE statement on French substitution policy. 24 January 2014 [homepage on the Internet]. 2014 Jan 24 [cited 2015 Feb 11]. Available from: http://www.ebe-biopharma.eu/newsroom/54/22/ EBE-statement-on-French-substitution-policy

18. European Commission. Report on a biologics workshop in Warsaw on 13 November 2014. [Biosimilar medicines can be treated as generic medicines with a wider scope of research in comparison to relation to the reference medicines, and therefore they can be applied interchangeably - convinced Igor RadziewiczWinnicki, Undersecretary of State in the Ministry of Health]. In Polish. [cited 2015 Feb 11]. Available from: http://ec.europa.eu/polska/news/141119_leki_pl.htm

19. Ministerstwo Zdrowia. Komunikat MZ-PLA-460-16300-118/BRB/14. 10 June 2014 Pismo MZ-PLA-460-15149-316/BRB/14. Wedlug rozdzielnika. 14 April 2014. [homepage on the Internet]. In Polish. [cited $2015 \mathrm{Feb}$ 11]. Available from: http://www.nfz-wroclaw.pl/download. ashx?id=/45418/pisma\%20MZ\% 20ws\%20lek\%F3w\%20biopodobnych.pdf

20. GKV Spitzenverband. Rahmenvertrag nach $₫ 129$ Absatz 2 SGB V, Paragraph 4(1), in connection with attachment 1 of the Framework Agreement on Medicinal Products Supply pursuant to Sec. 129 para 2 SGB V. 15 June 2012 [homepage on the Internet]. 2012 Jun 19 [cited 2015 Feb 11]. Available from: http:// www.gkv-spitzenverband.de/media/dokumente/krankenversicherung_1/ arzneimittel/rahmenvertraege/apotheken/AM_20120615_S_RVtg_129_Abs2.pdf

21. Agenzia Italiana del Farmaco. Position Paper sui farmaci biosimilari (28/05/2013) [homepage on the Internet]. 2013 May 27 [cited 2015 Feb 11]. Available from: http://www.agenziafarmaco.com/it/content/position-paper

22. Agencia Estatal Boletín Oficial del Estado. Spain: Orden SCO/ 2874/2007 of 28 September, Article 1 [homepage on the Internet]. [cited 2015 Feb 11]. Available from: http://www.boe.es/diario_boe/txt.php?id=BOE-A-2007-17420

23. Dylst $\mathrm{P}$, et al. Reference pricing systems in Europe: characteristics and consequences. Generics and Biosimilars Initiative Journal (GaBI Journal). 2012; 1(3-4):127-31. doi:10.5639/gabij. 2012.0103-4.028

24. Jusline. Rezeptpflichtgesetz, Art. 3 (1c) [homepage on the Internet]. [cited 2015 Feb 11]. Available from: http://www.jusline.at/Rezeptpflichtgesetz_(RezPG).html

25. Österreichische Apothekerkammer. Apothekergesamtvertrag, Art. 2 [homepage on the Internet]. [cited 2015 Feb 11]. Available from: http://www. apotheker.or.at/internet/OEAK/NewsPresse_1_0_0a.nsf/agentEmergency! OpenAgent\&p=4E4DD0F8172AD880C1257142002721F3\&fsn=fsStartHome Fachinfo\&iif $=0$

26. European Parliament. Kanavos P, et al. Differences in costs of and access to pharmaceutical products in the EU. 2010 [homepage on the Internet]. 2013 Mar 24 [cited 2015 Feb 11]. Available from: http://www.europarl.europa.eu/RegData/ etudes/etudes/join/2011/451481/IPOL-ENVI_ET(2011)451481_EN.pdf

27. Gesundheit Österreich GmbH (GOEG) WHO Collaborating Centre for Pharmaceutical Pricing and Reimbursement Policies. BouvyJ, Vogler S. Background Paper 8.3. Pricing and reimbursement policies: impacts on innovation. 2013 [homepage on the Internet]. 2013 Jun 28 [cited 2015 Feb 11]. Available from: http://whocc. goeg.at/Literaturliste/Dokumente/FurtherReading/Bouvy_PriorityMedicines_2013_ BP8_3_pricing.pdf

28. World Health Organization. Kaplan W, et al. Priority Medicines for Europe and the World. 2013 Update [homepage on the Internet]. 2013 Jul 8 [cited 2015 Feb 11]. Available from: http://www.who.int/medicines/areas/priority_ medicines/MasterDocJune28_FINAL_Web.pdf

29. EU Clinical Trials Register. Clinical trials for 2014-002056-40 [homepage on the Internet]. 2015 Feb 11 [cited 2015 Feb 11]. Available from: https://www. clinicaltrialsregister.eu/ctr-search/search?query $=2014-002056-40$

30. European Biopharmaceutical Enterprises. EBE Position Paper on tendering of biologicals, including biosimilars. 21 May 2012 [homepage on the Internet]. [cited 2015 Feb 11]. Available from: http://www.ebe-biopharma.eu/documents/3/22/ EBE-Position-Paper-on-Tendering-of-Biologicals-including-Biosimilars

31. EuropaBio. EuropaBio's position on tendering practices in biological medicines [homepage on the Internet]. 2010 Nov 19 [cited 2015 Feb 11]. Available from: http://www.europabio.org/sites/default/files/position/europabio_ position_on_tendering_practices.pdf

32. Grabowski H, Guha R, Salgado M. Biosimilar competition: lessons from Europe. Nat Rev Drug Discov. 2014;13(2):99-100.

33. EuropaBio. Pan-European survey calls for a shift in policy for biosimilars. 18 March 2010 [homepage on the Internet]. $2015 \mathrm{Feb} 11$ [cited $2015 \mathrm{Feb} 11$ ]. Available from: http://www.europabio.org/press/pan-european-survey-calls-shift-policybiosimilars

34. Leopold C, et al. Effect of the economic recession on pharmaceutical policy and medicine sales in eight European countries. Bull World Health Organ. 2014;92(9):630-40D.

35. Gesundheit Österreich GmbH (GOEG), WHO Collaborating Centre for Pharmaceutical Pricing and Reimbursement Policies (2015), Glossary; [cited 2015 Feb 11]. Available from: http://whocc.goeg.at/Glossary/PreferredTerms

36. European Biopharmaceutical Enterprises. EBE Position paper on recommendations on the use of biological medicinal products: substitution and related healthcare policies. http://www.ebe-biopharma.eu/priorities/biosimilars

DOI: 10.5639/gabij.2015.0401.006

Copyright $\odot 2015$ Pro Pharma Communications International 